\title{
STUDY OF AGE THRESHOLD OF TRAUMATIC MEMORY
}

Azarian A. (Office of Mental Health Practitioners, Providence, USA)

anait@cox.net

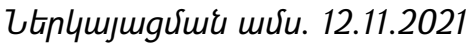

9nmunuर्यir mर्u. 20.11.2021

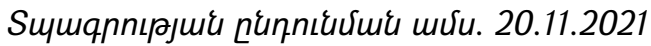

The article is devoted to the study of age threshold of traumatic memory. The study of memories of young children is started conducted in Children's Psychotherapy Center in Kirovakan (Vanadzor) who experienced the devastating Armenian earthquake in 1988 using the data collected during evaluations of the affected children.

The research has shown that the versatility of behavioral memory operates according to different rules than verbal one; it does not require verbal skills and conscious awareness and therefore, does not depend on the children's age.

Keywords: trauma, behavioral memory, verbal memory, children, simulation, rehabilitation.

DOI: https://doi.org/10.46991/SBMP/2022.5.1.020

There has been and still is a tremendous amount of interest regarding young children's ability to remember traumatic events. This issue has come under public scrutiny as a result of the rapidly increasing number of cases in which children are called to testify as witnesses to violence, or in which adults testify about abuse in their early childhood [1,3]. Very often, the accused who come to the attention of the public are individuals of previously distinguished service for society, which makes difficult for their families, friends and public to accept the possibility that they really have abused children. Many professionals, practicing clinicians and academicians have been addressing unending controversy concerning the reliability of retrieved traumatic childhood memories, or so-called "repressed traumatic memories vs. false implanted memories" [6, 9]. There have been attempts to verify the anecdotal clinical findings on the onset of childhood memories, reportedly having quite wide range from 1 year of age to 7, through the use of controlled laboratory experiments with groups of children and adults [4,5]. Unfortunately, these studies have produced disparities in results. The recent survey of research literature has showed that it is "still unclear that clinicians should refrain" from questioning patients about their early childhood memories due to fear that retrieved memories would be labeled as implanted fantasies and on the other hand risking not treating childhood trauma that may have been real [2]. Thus, establishing the earliest age or age threshold 
at which individuals can recall personally experienced traumatic events has profound implications not only in forensic field but also for proper therapeutic treatment of victimized patients.

My personal interest in learning more about the age threshold of traumatic memory has developed during my work at Bradley Children's Hospital: I wanted to know what stories of abuse and maltreatment told me by my young patients, mostly internationally adopted children, were true or invented. In process, I learned that many clinicians seriously question the reliability of experimental studies reliant on children or students studied in psychology labs which were unable to simulate real traumatic events because each real traumatic event may strongly influence the manner in which child perceives, understands, encodes, and remembers that event. For example, no research focused on early childhood memory has examined memory in young survivors of natural disasters. So, then I started this study of memories of young children who experienced the devastating Armenian earthquake in 1988 using the data collected during evaluations of the affected children, which I personally conducted in Children's Psychotherapy Center in Kirovakan.

The selected subjects were 90 toddlers aged at the time of the quake from 10 to 44 months and from 15 to 48 months at the time of evaluation. On average, the children were interviewed 6.7 months (or 6 months!) after the quake. Each child was evaluated using structured interviews. The questionnaire addressed not only diagnostic symptomatology but also the child's personal experience associated with traumatization in the quake. Considering the very young age of the children, the interviews took place in the presence of their parents or guardians. The children were given the opportunity to report the details of the trauma spontaneously-verbally, or with drawings and play activities. Interview questions were not designed to elicit specific assessment of completeness or inaccuracies in memory. Later, in this descriptive study based on the open-ended questions, we also refrain from assessing the fullness of toddler's memories: our goal was simply to establish the presence of quake verbal memory (from of elicit memory) at the time of the evaluation.

We concluded that a subject had a verbal memory of the quake if the child could spontaneously or with little cuing recall his or her personal quake experience, verified by an adult as true or quite possible. The memory could consist of a very short story, even just a few phrases, but it had to include what the young survivor saw, felt, heard, smelled, or how he or she acted, and of what he or she was scared. Of the 90 toddlers, more than half (53.3\%) produced verbal memories of what they personally experienced during the quake. This is about twice more (27.8\%) than toddlers who could exhibit any verbal memory 
about the experienced disaster. About one-fifth (18.9\%) of the toddlers refused to talk about the disaster issues or repeated the stories of others.

Many children were able to give vivid verbal descriptions of their personal experiences and recounted details of the tragic day that adults had not even noticed. They could remember the physical impact of the quake but were more likely to recall unusual behaviors or actions by significant ones.

Here is a direct statement from the boy, age 30 months at time of the disaster, whom I interviewed 8 months later: "The house broke in pieces. At first, all glass in windows broke...Dz-z-z..., then stones fell down from the roof. The roof also fell down, it fell down directly on our little apple tree. The tree broke and the house sat on the ground...I hate this house; I want my toys from the house."

A girl 33 recalled 5 months later: "My mother kept me in her arms and did not let me go by myself or stand near her. We were watching what our neighbors were dragging out from the building. Aunt Rosa came out with a big bowl with food. We stayed in the yard for a long time, but my father did not come. Mother cried, I didn't, I knew he would come. Also, I remember that people shouted to each other- 'Cut the light! Cut the gas!' Why they did say that? Do you know? Our cat was with us in the yard and then disappeared. So now, we have no cat. Then my father came, he was very dirty. He said: 'I am so glad you are safe and sound.'

The children in this study remembered very selectively, mostly what had some personal meaning for them or directly affected their interests. A child could notice and then recall the loss of her favorite doll, and yet could pay no attention to a multistoried building that had collapsed on her street. These small egocentrics would remember well how their totally confused and panicked parents behaved and unintentionally frightened them while rescuing them from dangerous places.

Children's age had considerable influence on their verbal memory abilities. Only $14.3 \%$ ( 3 from 21) of them who were 2 years or younger at the time of quake could recall something that had happened to them. Many more $61.5 \%$ (24 from 39) of age between 2 and 3 could and 70\% (21 from 30) with age from 37 to 44 months could provide verbal accounts of their personal experiences during the quake. The data we received gave us opportunity to determine the earliest age at which our children are able to recall the quake. We consider such age threshold accordingly to its generally accepted definition [10] - "the youngest age at which at least a little more than half subjects with verbal memory of the quake we were able to set apart age from 29 to 32 months determining average age threshold as 30.4 months; in this group $72.7 \%$ ( 8 from 11 ) verbally recalled their 
quake experiences, when in the younger age group ( $25-28$ months) only $41.7 \%$ ( 5 from 12) could do so.

Some previous studies [5, 7] have shown availability of earliest verbal memories of nontraumatic events (sibling birth) between ages of 3 and 4 years. Some clinicians [8, 9], who treated young patients of real traumatic events (plane crash, car accident, kidnapping), reported that children as young as 26-28 months could verbalize a clear description of their traumatic experiences which happened a few months earlier. Average age threshold of 30.4 months (29-32 months) that was determined in our study reaffirms the opinion that emotionally profound, life-threatening traumatic events may be recorded and remembered by younger children than by children who experienced common stressful events or events artificially simulated in labs. Age threshold of remembering personally significant life events serves as the onset of autobiographical memory in the establishment of self, "something that happened to ME" [4], the age that coincides with the developmental stage when children begin constructing grammatically ordered phrases enabling them to express some inner feelings verbally as well as mentally recorded experiences.

Recorded traumatic memories can be recovered not only verbally but explicitly, for example, through behavioral changes such as avoidance, detachment, fears, aggression, trauma replays and repetitive drawings, and unusual psychosomatic reactions (sweating, agitation, freezing, headaches, etc.).

We found that in difference to verbal memory the overwhelming majority of the toddlers $90 \%$ ( 81 from 90) demonstrated presence of nonverbal form of the quake's memory. Even children in the youngest age group from 10 to 24 months, 18 from 21 or $85.7 \%$ did so. The prevailing part of children (63.3\%) expressed their memory of the quake through new and unusual physical stimuli that reminded them of their psychosensory experience during the disaster (loud noises, vibrations, the smell of fire or dust, and so on). One boy of age 18 months was asleep when the quake began; he was awakened by the people's shouts and screams, and the sounds of things falling and braking in the apartment. Eight months later, he still shuddered and cried in response to his parents talking loudly, sounds of cars on the street or the sound of the vacuum machine. The universality of behavioral memory shows that it operates by different rules than verbal memory; it does not require verbal skills and conscious awareness and therefore does not depend on the children's age. Young children are perfect learners and their explicitly recorded behavioral memories are adapted for warning, avoiding, freezing, and flight/fight reactions without long, time-consuming conscious processes and may serve as surviving skills in a hostile environment. 


\section{References}

1. Ceci, S.J., \& Bruck, M. (1950). Jeopardy in the courtroom: A scientific analysis of children's testimony. Washington, DC: American Psychological Association.

2. Goodman, G.S., Gonzalves, L.,Wolpe, S. (2019). False Memories and True Memories of childhood Trauma: Balancing the Risks. Clinical Psychological Science, 7(1), pp. 29-31, doi.org/10.1177/2167702618797106.

3. Goodman, G.S., Goldfarb, D., et al. (2017). Psychological counseling and accuracy of memory for child sexual abuse. American Psychologist, p. 72, 920-931, doi.org/10.1037/amp0000282.

4. Howe, M. (2011). The Nature of Early Memory. New York, NY: Oxford UP.

5. Kihlstrom, J.F., \& Haraskiewicz, J.M. (1982). The earliest recollection: A new survey. Journal of Personality, p. 50, 134-148, doi.org/10.1111/j.1467-6494.1982.tb01019.x

6. Loftus, E. F. (1993). The reality of repressed memories. American Psychologist, 48 (5), pp. 518-537, doi.org/10.1037/0003066X.48.5.518.

7. Loftus, E. F. (1993). The reality of repressed memories. American Psychologist, 48 (5), pp. 518-537, doi.org/10.1037/0003066X.48.5.518.

8. Sugar, M. (1992). Toddlers' traumatic memories. Infant Mental Health Journal, 13 (3), pp. 245-251, https://doi.org/10.1002/10970355(199223)13:3<245::AID-IMHJ2280130310>3.0.CO;2-4

9. Terr, L.C. (1994). Unchained memories: True stories of traumatic memories lost and found. New York, NY: Basic Books.

10. Usher, J. N., \& Neisser, U. (1993). Childhood amnesia and the beginnings of memory for four early life events. Journal of Experimental Psychology: Genaral, p. 122, pp. 155-165. DOI: 10.1037/00963445.122.2.155

11. Williams, L. M. (1994). Recall of childhood trauma: A prospective study of women's memories of child sexual abuse. Journal of Consulting and Clinical Psychology, 62 (6), pp. 1167-1176, DOI: 10.1037//0022006X.63.3.343. 